\title{
Thyrocalcitonin and the Jejunal Absorption of Calcium, Water, and Electrolytes in Normal Subjects
}

\author{
T. Kenney Gray, Frederick A. Bieberdorf, and John S. Fordtran \\ From the Department of Internal Medicine and Pharmacology, University of \\ North Carolina Medical School, Chapel Hill, North Carolina 27514, and the \\ Department of Internal Medicine, The University of Texas Southwestern \\ Medical School, Dallas, Texas 75235
}

A B S T R A C T Jejunal absorption of calcium, water, and
electrolytes was measured in 10 normal subjects by the
triple-lumen perfusion method. During the control pe-
riod, water and electrolyte movements were minimal when
a bicarbonate-free test solution was infused. By contrast,
bicarbonate-containing solutions were readily absorbed
in the control period. Intravenous infusion of synthetic
salmon calcitonin (SCT) ( 1 Medical Research Council
$\mathrm{U} / \mathrm{kg}$ wt/h) over $110-120$ min resulted in a marked
jejunal secretion of water, sodium, potassium, and chlo-
ride in 8 of the 10 subjects. This jejunal secretion oc-
curred with both the bicarbonate-free and the bicarbo-
nate-containing test solutions. Calcium absorption was
not affected by SCT, and the serum calcium concentra-
tion did not fall during SCT infusion. These results
suggest that diarrhea in patients with medullary carci-
noma of the thyroid may be due to intestinal secretion
secondary to high blood concentrations of thyrocalcitonin.

\section{INTRODUCTION}

Several lines of evidence suggest that gastrointestinal hormones may be mediators of thyrocalcitonin release and that thyrocalcitonin may influence gastrointestinal function. First, in experimental animals, gastrin and possibly other gastrointestinal hormones act as secretagogues for the release of thyrocalcitonin (1). A stimulus for this gastrin-thyrocalcitonin interaction is apparently the presence of calcium ions within the gastrointestinal tract (2). Second, thyrocalcitonin has been reported to alter the rate of calcium absorption. Specifically, ${ }^{45} \mathrm{Ca}$ absorption in the rat intestine in vitro was depressed by thyrocalcitonin (3), and the fecal excretion of calcium was decreased by the administration of pharmacologic

Received for publication 21 May 1973 and in revised form 20 July 1973. amounts of thyrocalcitonin to patients with Paget's disease (4). Third, patients with medullary carcinoma of the thyroid have very high levels of thyrocalcitonin, and many of these patients have severe diarrhea $(5,6)$. Although it has not been previously suggested that this diarrhea is due to thyrocalcitonin excess, the occurrence of gastrointestinal symptoms in patients with medullary carcinoma of the thyroid raises the possibility that thyrocalcitonin may have an effect on gastrointestinal motility and/or on the absorption of water and electrolytes.

The purpose of our studies was to determine the influence of synthetic salmon calcitonin $(\mathrm{SCT})^{1}$ on net transport of water, electrolytes, and calcium in the jejunum of normal human subjects.

\section{METHODS}

Absorption in a $40 \mathrm{~cm}$ segment of proximal jejunum was studied by the triple-lumen perfusion system that has been previously described in detail $(7,8)$. The method involves perfusion of test solutions into the small intestine and continuous sampling of the gut contents 10 and $50 \mathrm{~cm}$ beyond the infusion point. Polyethylene glycol (PEG) was the nonabsorbable volume marker. Experiments were begun when the infusion site was at the ligament of Treitz as determined by fluoroscopy.

The subjects were normal volunteers, ages $21-40$, who granted an informed consent. None had positive reactions to a skin test with SCT.

The first five subjects were perfused with an isotonic bicarbonate-free test solution designed, on the basis of previous studies (9), so that net water and sodium movement would be near zero in the control period. This solution contained $\mathrm{NaCl}(116 \mathrm{mM}), \mathrm{KCl}(4 \mathrm{mM})$, mannitol (35 $\mathrm{mM})$, calcium gluconate $(5 \mathrm{mM})$, and PEG (5 g/liter). The experimental protocol was $7 \mathrm{~h}$ in duration and consisted of the following: equilibration $(1 \mathrm{~h})$, control (two 1-h test periods), SCT infusion (two 1-h test periods), and postinfusion control (two 1 -h test periods).

${ }^{1}$ Abbreviations used in this paper: PEG, polyethylene glycol; SCT, salmon calcitonin. 

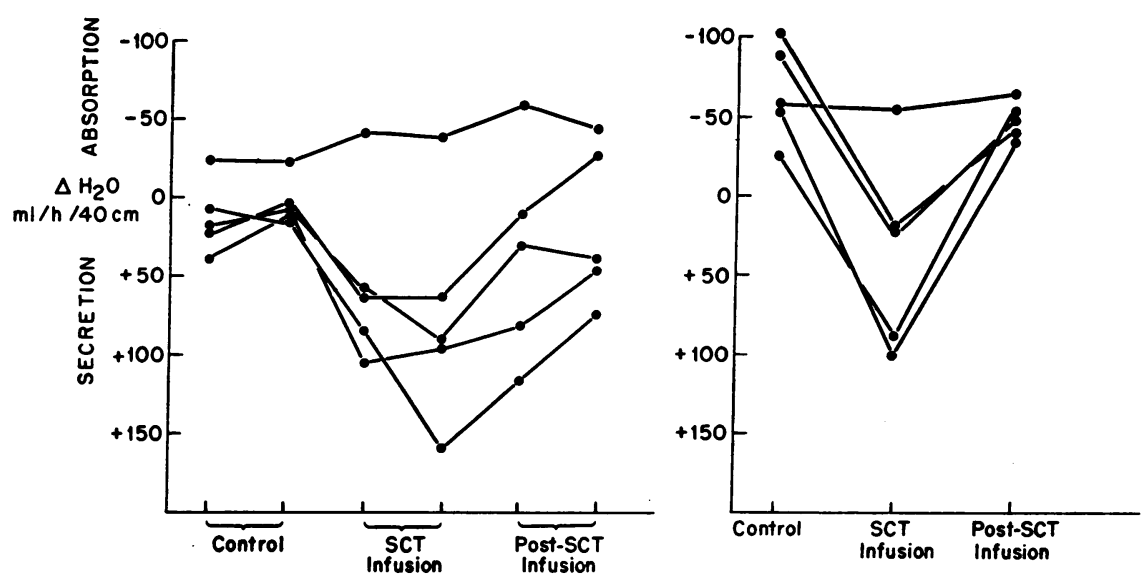

Figure 1 Water movement $\left(\Delta \mathrm{H}_{2} \mathrm{O}\right)$ in the jejunum of 10 subjects, 5 receiving the bicarbonate-free solution and 5 receiving the bicarbonate-containing solution. Two 1-h study periods were obtained during the control, SCT and post-SCT periods when the bicarbonatefree solution was infused.

The next five subjects were perfused with an isotonic bicarbonate-containing solution that is readily absorbed in the jejunum of normal subjects. This solution contained $\mathrm{NaCl}(105 \mathrm{mM}), \mathrm{NaHCO}_{3}(30 \mathrm{mM}), \mathrm{KCl}(4 \mathrm{mM})$, calcium gluconate $(5 \mathrm{mM})$, and PEG $(5 \mathrm{~g} /$ liter $)$. The experimental protocol for this group of subjects was approximately $5 \frac{2}{3} \mathrm{~h}$ : equilibration $(1 \mathrm{~h})$, control $(1 \mathrm{~h})$, SCT infusion (equilibration $50 \mathrm{~min}$, followed by a $1 \mathrm{~h}$ test period), and postinfusion control (equilibration $50 \mathrm{~min}$, followed by a $1 \mathrm{~h}$ test period).

The rate of intestinal perfusion was $11 \mathrm{ml} / \mathrm{min}$ in all subjects. Test solutions containing bicarbonate were bubbled with $5 \% \quad \mathrm{CO}_{2}-95 \% \quad \mathrm{O}_{2}$ for $30 \mathrm{~min}$ before and during the experiments. Intestinal samples were aspirated from the proximal and distal apertures of the tube at a rate of 1 $\mathrm{ml} / \mathrm{min}$ into plastic syringes that were capped immediately after the collection of each $30 \mathrm{~min}$ pool.

Salmon calcitonin ${ }^{2}$ (SCT, AL0997) (1 Medical Research Council $\mathrm{U} / \mathrm{kg} \mathrm{wt} / \mathrm{h}$ ) was diluted in $0.9 \%$ saline and infused i.v. at the rate of $0.5 \mathrm{ml} / \mathrm{min}$. Equal volumes of saline were infused during the control and postinfusion periods in all subjects.

Blood samples were obtained serially throughout the experiments and centrifuged. The sera were stored at $-20^{\circ} \mathrm{C}$ until analysis was performed.

The fluid aspirated from the intestine was analyzed for $\mathrm{pH}$, osmolality, and concentrations of electrolytes and PEG by methods that have been previously described (7-10). Serum and intestinal calcium concentrations were determined by atomic absorption spectrophotometry as described elsewhere (11). Absorption or secretion rates were calculated from the perfusion rate, the change in concentration of the nonabsorbable marker, and the change in concentration of electrolytes and calcium (7-11). The values for net water and electrolyte movement are expressed as mean values \pm 1 SEM. Statistical analysis is based on the paired $t$ test.

${ }^{2}$ Generously provided by Dr. James Lesh, Armour Pharmaceutical Co., Chicago, Ill. Potency of lot K483216 is 4,334 Medical Research Council U/mg.

\section{RESULTS}

\section{Movement of water and electrolytes}

Control period. As shown in Table I and Fig. 1, the net movements of water, sodium, and potassium with the bicarbonate-free solution were near zero, which is consistent with the design of the perfusion solution. Chloride was absorbed, and bicarbonate was secreted at rates of about $4 \mathrm{meq} / \mathrm{h} / 40 \mathrm{~cm}$. The net movement of these anions was in the direction favored by the concentration gradients of chloride and bicarbonate across the intestinal mucosa.

With the bicarbonate-containing test solution water and sodium were readily absorbed (Table I and Fig. 1). These observations are consistent with previous reports that the presence of bicarbonate in the luminal fluid stimulates sodium absorption, most likely through a stimulation of Na-H exchange (12).

SCT infusion. SCT infusion was associated with jejunal secretion of water, sodium, potassium, and chloride in 8 of the 10 subjects. Individual values for water movement before, during, and after the SCT infusion in both groups of subjects are depicted in Fig. 1.

The mean value for water secretion with the bicarbonate-free solution (Table I) was $64 \mathrm{ml} / 40 \mathrm{~cm} / \mathrm{h}$, which is an eightfold increase over the slight rate of water secretion in the control period. Comparable increases in the sodium and potassium secretion also occurred. Chloride, which was absorbed during the control period (down a concentration gradient), was secreted during the SCT infusion (against a concentration gradient). The rate of bicarbonate secretion increased from a con- 
TABLE I

Net Moiement $(\triangle)$ of Water, Electrolytes, and Calcium in 10 Subjects before, during, and after SCT Infusion*

\begin{tabular}{lccc}
\hline \multicolumn{2}{c}{ Control } & SCT infusion & Postinfusion \\
\hline Bicarbonate-free solution & & \\
$\Delta \mathrm{H}_{2} \mathrm{O}$ & $+8 \pm 6.0$ & $+64.0 \pm 0.20$ & $+26.0 \pm 0.18$ \\
$\Delta \mathrm{Na}$ & $+1.4 \pm 0.9$ & $+9.9 \pm 2.4$ & $+4.8 \pm 2.0$ \\
$\Delta \mathrm{K}$ & $-0.03 \pm 0.05$ & $+0.29 \pm 0.09$ & $+0.13 \pm 0.1$ \\
$\Delta \mathrm{Cl}$ & $-3.6 \pm 1.6$ & $+1.4 \pm 2.1$ & $-0.4 \pm 1.5$ \\
$\Delta \mathrm{HCO}{ }_{3}$ & $+4.0 \pm 0.9$ & $+6.5 \pm 1.5$ & $+4.8 \pm 1.0$ \\
$\Delta \mathrm{Ca}$ & $-0.29 \pm 0.08$ & $-0.29 \pm 0.06$ & $-0.43 \pm 0.07$ \\
$\mathrm{Bicarbonate}$-containing solution & & \\
$\Delta \mathrm{H}_{2} \mathrm{O}$ & $-65.0 \pm 13.0$ & $+36.0 \pm 28.0$ & $-48.0 \pm 5.0$ \\
$\Delta \mathrm{Na}$ & $-7.6 \pm 1.9$ & $+7.3 \pm 3.6$ & $-5.1 \pm 0.9$ \\
$\Delta \mathrm{K}$ & $-0.49 \pm 0.10$ & $-0.03 \pm 0.09$ & $-0.34 \pm 0.02$ \\
$\Delta \mathrm{Cl}$ & $-2.6 \pm 2.0$ & $+7.2 \pm 2.7$ & $-1.4 \pm 2.2$ \\
$\Delta \mathrm{HCO}$ & $-3.3 \pm 1.2$ & $-0.04 \pm 2.0$ & $-2.5 \pm 1.3$ \\
$\Delta \mathrm{Ca}$ & $-0.26 \pm 0.07$ & $-0.15 \pm 0.07$ & $-0.31 \pm 0.07$ \\
\end{tabular}

Statistical analyses: In the subjects given the bicarbonatefree solution, the changes during the SCT infusion for $\Delta \mathrm{H}_{2} \mathrm{O}$ were significant at $P<0.05$ and for $\Delta \mathrm{Na}$ and $\Delta \mathrm{K}$ at $P<0.01$. In the subjects given the bicarbonate-containing solution, the changes during the SCT infusion for $\Delta \mathrm{H}_{2} \mathrm{O}, \Delta \mathrm{K}$, and $\Delta \mathrm{Cl}$ were significant at $P<0.05$ and for $\Delta \mathrm{Na}$ at a $P$ of $<0.01$. Combined analysis of 10 subjects showed the changes during SCT infusion for $\Delta \mathrm{H}_{2} \mathrm{O}, \Delta \mathrm{Na}, \Delta \mathrm{K}$, and $\Delta \mathrm{Cl}$ to be significant at $P<0.005$ whereas $\triangle \mathrm{HCO}_{3}$ was significant at $P<0.02$. Other changes were NS.

* Mean values $( \pm 1 \mathrm{SEM}$ ) expressed as $\mathrm{ml} / 40 \mathrm{~cm} / \mathrm{h}$ for water, $\mathrm{mmol} / 40 \mathrm{~cm} / \mathrm{h}$ for calcium, and $\mathrm{meq} / 40 \mathrm{~cm} / \mathrm{h}$ for electrolytes. $(-)=$ net absorption and $(+)=$ net secretion.

trol value of 4 to a value of $6.5 \mathrm{meq} / \mathrm{h} / 40 \mathrm{~cm}$ during $\mathrm{SCT}$ infusion.

The influence of SCT infusion on net water and electrolyte movement was greater when the bicarbonatecontaining solution was infused (Table I). Water and electrolytes were uniformly absorbed in the control period, whereas secretion of water, sodium, and chloride occurred with SCT. The difference in the mean control and SCT infusion values for water movement is 101 $\mathrm{ml} / 40 \mathrm{~cm} / \mathrm{h}$, nearly double the response observed with the bicarbonate-free solution. Changes of a comparable magnitude occurred in the movement of sodium and chloride. Potassium and bicarbonate absorption were markedly diminished, to values near zero, during SCT infusion.

As indicated in Fig. 1, 8 of the 10 subjects exhibited a secretory response during the SCT infusion. Two subjects, one in each group, had no response to the SCT infusion. When the paired differences of the 10 subjects were analyzed as a single group, the changes during the SCT infusion of the movement of water, sodium, potassium, and chloride were highly significant $(P<0.005)$.
Similarly, the changes in bicarbonate movement were significant at a $P$ value of $<0.02$.

Postinfusion period. The mean values for the movement of water and all electrolytes returned toward the control level in the postinfusion period.

\section{$\mathrm{pH}$ and bicarbonate concentrations}

The $\mathrm{pH}$ values of luminal fluid, collected from the distal aspiration site during perfusion of the bicarbonatefree solution, varied between 6.83 and 7.07 . With the bicarbonate-containing solution, $\mathrm{pH}$ varied between 7.00 and 7.29. The $\mathrm{pH}$ and bicarbonate concentration of luminal fluid were slightly but significantly higher $(P<$ 0.05 ) during SCT infusions than in the control periods. in agreement with the decreased rate of bicarbonate absorption noted above.

\section{Calcium absorption}

Calcium was absorbed with both test solutions during the control period (Table I). The mean values for calcium absorption are nearly identical in the two groups, -0.29 and $-0.26 \mathrm{mmol} / 40 \mathrm{~cm} / \mathrm{h}$. These values are in close agreement with the calcium absorption rates observed previously in normal young adults (11). No significant changes in calcium absorption or the luminal concentrations of calcium occurred during the SCT infusion.

\section{Serum calcium concentration}

Serum calcium concentrations, determined in blood samples obtained before and serially after the beginning of the 110-120 min i.v. infusion of SCT, are given in Table II. The mean values of the serum calcium in both groups during the experiments are not significantly different.

\section{DISCUSSION}

The dose of SCT infused in these subjects was selected because the previous experience of one of the authors

TABLE II

Total Serum Calcium before, during, and after $S C T$ Infusion, Mean $\pm S E M$

\begin{tabular}{lcc}
\hline & Group 1 & Group 2 \\
\hline $\begin{array}{l}\text { Control } \\
\begin{array}{l}60 \text { min after beginning } \\
\text { SCT infusion }\end{array}\end{array}$ & $9.81 \pm 0.11$ & $9.33 \pm 0.2$ \\
$\begin{array}{l}110-120 \text { min after beginning } \\
\text { SCT infusion }\end{array}$ & $9.77 \pm 0.14$ & $9.23 \pm 0.22$ \\
$\begin{array}{l}110-120 \text { min after the end } \\
\text { of SCT infusion }\end{array}$ & $9.49 \pm 0.19$ & $9.14 \pm 0.22$ \\
& $9.42 \pm 0.25$ & $9.23 \pm 0.24$
\end{tabular}

* Values are expressed as $\mathrm{mg} / 100 \mathrm{ml}$. 
(unpublished observations, Dr. Gray) showed that it led to little or no fall in the serum calcium level under similar circumstances. The absence of a fall in the serum calcium permitted us to observe the effects of the infused SCT without the added influence of hypocalcemia. The blood levels of SCT attained by our infusion of SCT can be estimated from the distribution volume and halflife of SCT. Assuming a distribution volume equal to that of the extracellular fluid and a half-life of approximately $20 \mathrm{~min}^{3}$ it is estimated that the blood concentration of SCT ranged from several hundred picograms per milliliter during the early part of the infusion to a few nanograms toward the end of the infusion. These levels are lower by 10 - to 20 -fold than the blood levels of thyrocalcitonin reported in patients with medullary carcinoma of the thyroid gland $(5,6)$. The selected dose of SCT approximates that currently used for the treatment of Paget's disease (4) and is less than that reported to reduce gastric acid secretion (13).

Initially we thought that the jejunal absorption of calcium might be altered by SCT since earlier reports suggested alterations in the intestinal transport of calcium by thyrocalcitonin $(3,4)$. No statistically significant alteration in the rate of jejunal calcium absorption during SCT infusion was found. The differences between our results and previous reports may be methodologic (in vivo vs. in vitro methods), related to species differences, to the duration of treatment, or to dosage employed. In any event, our results provide no evidence that thyrocalcitonin regulates directly the intestinal absorption of calcium. Indirect influences of a chronic nature, such as an effect of thyrocalcitonin on the renal hydroxylation of vitamin D metabolites, have been suggested by other workers (14).

The most striking finding in the present studies is that the SCT infusion induces a marked jejunal secretion of water, sodium, chloride, and potassium and reduces jejunal bicarbonatae absorption. The effect of SCT is prompt, being noted during the $1 \mathrm{st} h$ after SCT infusion was started, and it is reversible since net movement of water and electrolytes returned toward control within 1 $\mathrm{h}$ after SCT infusion was stopped.

The mechanism of this secretory process is not known, although chloride was secreted against a concentration gradient when the bicarbonate-free test solution was infused (i.e., chloride was secreted even though luminal chloride concentration was 20-25 meq/liter higher than in plasma). This suggests that SCT induces active chloride secretion. Proof of this hypothesis must await simultaneous measurements of net ion transport and potential

\footnotetext{
${ }^{3}$ The half-life of SCT in man is estimated from a consideration of the comparative half-lives of salmon and porcine hormones in experimental animals and the half-life of porcine thyrocalcitonin, $2.4 \mathrm{~min}$, in man (1).
}

difference across the jejunal mucosa under experimental conditions where water movement cannot affect net chloride movement by solvent drag (9).

The fact that SCT infusion results in jejunal secretion of water and electrolytes suggests that high blood levels of thyrocalcitonin might induce diarrhea. Indeed, the rates of fluid secretion during SCT infusion, 60-100 $\mathrm{ml} / 40 \mathrm{~cm} / \mathrm{h}$, are compatible with the production of severe diarrhea when extrapolated over the $300 \mathrm{~cm}$ of human small intestine, even allowing for possible colonic reabsorption of a fraction of the secreted fluid. Furthermore, two of five subjects given the same dose of SCT after the ingestion of a normal meal (but not receiving intestinal infusion of test solution) developed diarrhea within 1-2 $\mathrm{h}$ of the cessation of the SCT infusion (15).

These considerations suggest that the diarrhea of some subjects with medullary carcinoma of the thyroid may be explained by intestinal secretion secondary to high blood levels of thyrocalcitonin. Diarrhea in these patients is typically watery and large in volume. These features are characteristic of a secretory diarrhea (16). The fact that two of our normal subjects did not secrete in response to SCT is consistent with the observation that not all paients with this neoplasm have diarrhea and that the diarrhea may be intermittent. Others have attributed the diarrhea of medullary carcinoma of the thyroid to prostaglandins, which are present in excessive amounts in tumor extracts and the blood of these patients (6). It is, of course, possible that both prostaglandins and thyrocalcitonin may contribute to the diarrhea of these patients, but our data suggest that elevated blood levels of thyrocalcitonin alone might explain a secretory diarrhea.

\section{ACKNOWLEDGMENTS}

The authors wish to thank Martha Irvin and Barbara Bailey for technical assistance in the perfusion studies, Vicki Jones and Stephen Morawski for the analytical determinations, and Jean Harber, Carolyn Wickwire, and Kathy Dodson for typing the manuscript.

The study was supported by Grant 5 R01 AM 06506 from the National Institutes of Health.

\section{REFERENCES}

1. Gray, T. K., C. W. Cooper, and P. L. Munson. 1974. Parathyroid hormone, thyrocalcitonin and the control of mineral metabolism. In International Review of Science, Medical Technical Publications. Butterworth \& Co., Ltd., London.

2. Cooper, C. W., T. K. Gray, J. D. Hundley, and A. M. Mahgoub. 1971. Secretion of thyrocalcitonin and its regulation. Excerpta Med. Int. Congr. Ser. 238: 349.

3. Olson, E. B., Jr., H. F. DeLuca, and J. T. Potts, Jr. 1972. Calcitonin inhibition of vitamin D-induced intestinal calcium absorption. Endocrinology. 90: 151.

4. Shai, F., R. K. Baker, and S. Wallach. 1971. The clinical and metabolic effects of porcine calcitonin on Paget's disease of bone. J. Clin. Invest. 50: 1927. 
5. Deftos, L. J., A. E. Bury, J. F. Habener, F. R. Singer, and J. T. Potts, Jr. 1971. Immunoassay for human calcitonin. II. Clinical studies. Metab. (Clin. Exp.). 20: 1129.

6. Melvin, K. E. W., A. H. Tashjian, Jr., and H. H. Miller. 1972. Studies in familial (medullary) thyroid carcinoma. Recent Prog. Horm. Res. 28: 399.

7. Cooper, H., R. Levitan, J. S. Fordtran, and F. J. Ingelfinger. 1966. A method for studying absorption of water and solute from the human small intestine. Gastroenterology. 50: 1 .

8. Fordtran, J. S. 1966. Marker perfusion techniques for measuring intestinal absorption in man. Gastroenterology. 51: 1089.

9. Fordtran, J. S., F. C. Rector, Jr., and N. W. Carter. 1968. The mechanisms of sodium absorption in the human small intestine. J. Clin. Invest. 47: 884.

10. Fordtran, J. S., F. C. Rector, Jr., M. F. Ewton, N. Soter, and J. Kinney. 1965. Permeability characteristics of the human small intestine. J. Clin. Invest. 44: 1935.
11. Ireland, P., and J. S. Fordtran. 1973. Effect of dietary calcium and age on jejunal calcium absorption in humans studied by intestinal perfusion. J. Clin. Invest. $52: 26 \% 2$.

12. Turnberg, L. A., J. S. Fordtran, N. W. Carter, and F. C. Rector, Jr. 1970. Mechanism of bicarbonate absorption and its relationship to sodium transport in the human jejunum. J. Clin. Invest. 49: 548.

13. Hesch, R. D., B. Hasenhager, and W. Creutzfeld. 1971. Inhibition of gastric secretion by calcitonin in man. Horm. Metab. Res. 3: 140.

14. Rasmussen, H., M. Wong, D. Bikle, and D. B. P. Goodman. 1972. Hormonal control of the renal conversion of 25-hydroxycholecalciferol to 1,25-dihydroxycholecalciferol. J. Clin. Invest. 51: 2502.

15. Bieberdorf, F. A., T. K. Gray, and J. S. Fordtran. 1974. Inhibition of meal-stimulated acid secretion by thyrocalcitonin in man. Gastroenterology. In press.

16. Fordtran, J. S. 1973. Diarrhea. In Gastrointestinal Disease. M. S. Sleisenger and J. S. Fordtran, editors. W. B. Saunders Company, Philadelphia. 291. 